\title{
Socio-demographic Study for Prevalence of $\beta$-Thalassaemia and Haemoglobinopathies in Chattagram Maa Shishu-O-General Hospital
}

\author{
Razia Sultana ${ }^{1 *}$ \\ Anjir Anwar ${ }^{2}$ \\ Jahangir Alam ${ }^{2}$ \\ Mahmood A. Chowdhury2
}

'Department of Pathology

Chattagram Maa-O-Shishu Hospital Medical College Chittagong, Bangladesh.

${ }^{2}$ Department of Paediatrics Chattagram Maa-O-Shishu Hospital Medical College Chittagong, Bangladesh.
*Correspondence to:

\section{Dr. Razia Sultana}

Associate professor

Department of Pathology,

Chattagram Maa-O-Shishu Hospital Medical College

Chittagong, Bangladesh.

Mobile: +88 017119090533

Email: razialucky24@gmail.com

www.banglajol.info/index.php/CMOSHMCJ

\begin{abstract}
Background: Hemoglobin E beta thalassaemia is common hemolytic anemia in South-East Asia. Though Bangladesh is situated in a Thalassaemia prone region but there is no published data regarding spectrum of disease pattern of Hemoglobinopathies. This study done to see the prevalence of $\beta$ Thalassaemia and other haemoglobinopathies in patient attended the Chattagram Maa-Shishu O General Hospital. Methods: This is a retrospective descriptive study that was carried out in Chattagram Maa Shishu-O-General Hospital. Patient with Thalassaemia and other Hemoglobinopathies $(n=290)$ of different ages attended the Thalassaemia ward during the period from 2011 July to 2013 June were enrolled as study subject. Detailed history and hemoglobin electrophoresis result were obtained from patient register book. Analysis was done with the help of Statistical Package for Social Science (SPSS Version 12.0) software package. Results: It was observed that the onset of Haemoglobinopathies was significantly high from infant to childhood period (1-10 yr) with a percentage of $53 \%(p<0.05)$. Male and female difference was found statistically insignificant $(p>0.05)$. The prevalence of HBE $\beta$ Thalassaemia patients was found highest in percentage (40.34\%). Conclusion: $\mathrm{Hb}$ E $\beta$-Thalassaemia was the most common variety among all types of Hemoglobinopathies.
\end{abstract}

Key words: Thalassaemia; Hb E $\beta$-Thalassaemia; Socio-demographic study.

\section{INTRODUCTION}

Thalassaemia is an important health burden in many parts of Asia, especially in Bangladesh $^{1}$. Approximately $3 \%$ of the populations are the carriers of $\beta$ Thalassaemia and $4 \%$ are the carriers of $\mathrm{HbE} \beta$ Thalassaemia as per WHO reports in Bangladesh. This amounts to a total of 3.6 million carriers of $\beta$ Thalassaemia and 4.8 million carriers of $\mathrm{HbE} \beta$ Thalassaemia ${ }^{2}$. The family of a Thalassaemic child bears a heavy economical burden for the cost of treatment since it is not free in Bangladesh. Moreover, the facilities for pre-natal screening are scarce in our country even though it is a key method for prevention ${ }^{3}$. The carrier screening program is important for creating awareness among general public, but there is not any unified program in national level outlining public awareness. The country lacks any data about status and distribution of Thalassaemia carrier ${ }^{4}$. Measures should be taken to reduce the birth of a Thalassaemic child. This study was conducted to see the prevalence of various types of Thalassaemia between different age groups in Chittagong. The effective treatment of Thalassaemia is bone marrow transplantation, but it is very expensive and currently not available in Bangladesh. The best ways to prevent Thalassaemia are carrier screening, creating mass awareness about this emerging problem and to perform prenatal diagnosis ${ }^{5}$. 


\section{MATERIAL AND METHODS}

This is a retrospective descriptive study from July 2011 to June 2013 that is carried out from the records of the patients admitted in Chattagram Maa Shishu-O-General Hospital. A total 600 randomly suspected patients was taken, among them 290 patient were directly linked with different types of Thalassaemia. Patient details were obtained from register book of Thalassaemia ward. Hemoglobin electrophoresis result was collected from the laboratory. Coding Analysis was performed by Statistical Package for Social Science (SPSS Version 12.0) software package. Chi square test was done to compare the values between the groups as appropriate. The minimum level of significance was $p=0.05$. Tables are given to present data and results.

\section{RESULTS}

Figure 1: Distribution of study subject according to sex.

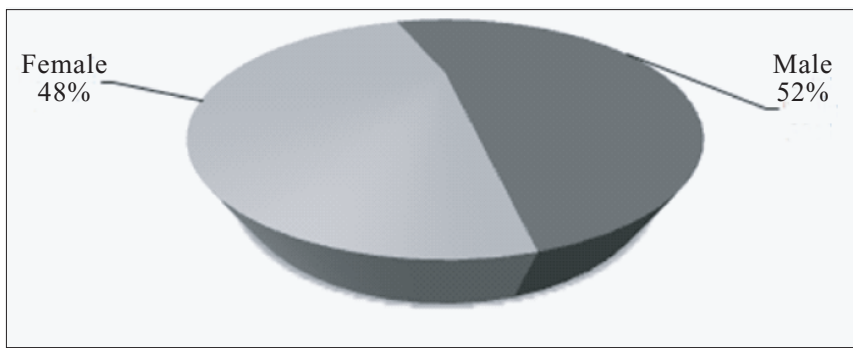

Figure 1 shows 52\% male and $48 \%$ female patient.

Figure 2 : Distribution of study subject according to different category of Thalassaemia.

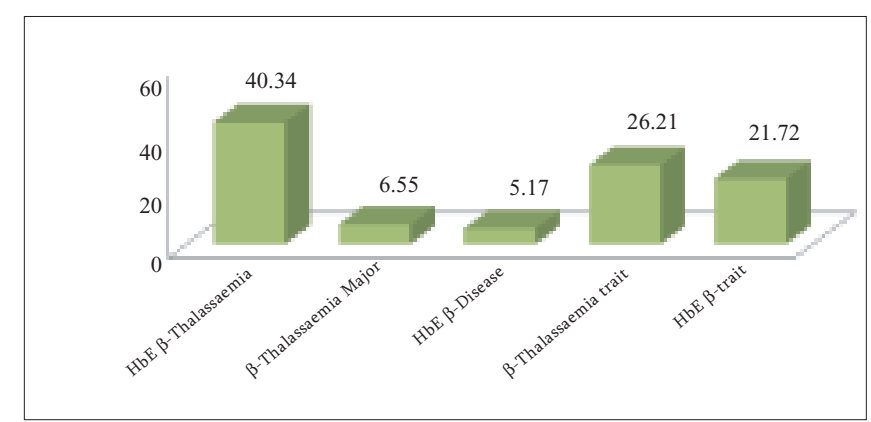

Figure 2 shows $\mathrm{Hb} \mathrm{E} \beta$-Thalassaemia was $40.34 \%, \beta$-Thalassaemia Major 6.55\%, Hb E Disease $5.17 \%$, $\beta$-Thalassaemia trait $26.21 \%$ and $\mathrm{Hb}$ E trait $21.72 \%$. The percentage of $\mathrm{Hb}$ E $\beta$-Thalassaemia patients (40.34\%) was the highest.

Table 1 : Distribution of types of Thalassaemia according to age and sex.

$\begin{array}{lcrrr}\text { Types of disease } & \begin{array}{c}\text { Age group } \\ \text { (Years) }\end{array} & \text { Male } & \text { Female } & \text { Total } \\ \text { Hb E ß-Thalassaemia } & <1-10 & 39(33.33) & 36(30.77) & 75(64.10) \\ & 11-20 & 11(9.40) & 10(8.55) & 21(17.95) \\ & 21-30 & 10(8.55) & 3(2.56) & 13(11.11) \\ & >30 & 5(4.27) & 3(2.56) & 8(6.84) \\ & \text { Total } & 65(55.56) & 52(44.44) & 117(100)\end{array}$

\begin{tabular}{|c|c|c|c|c|}
\hline \multirow[t]{5}{*}{$\beta$-Thalassaemia major } & $<1-10$ & $12(63.16)$ & $7(36.84)$ & $19(100)$ \\
\hline & $11-20$ & 0 & 0 & 0 \\
\hline & $21-30$ & 0 & 0 & \\
\hline & $>30$ & 0 & 0 & 0 \\
\hline & Total & $12(63.16)$ & $7(36.84)$ & 19(100) \\
\hline \multirow[t]{5}{*}{$\mathrm{HbE}$ disease } & $<1-10$ & $4(26.67)$ & $3(20.00)$ & $7(46.67)$ \\
\hline & $11-20$ & $3(20.00)$ & $3(20.00)$ & $6(40.00)$ \\
\hline & $21-30$ & $1(6.67)$ & $1(6.67)$ & $2(13.33)$ \\
\hline & $>30$ & 0 & 0 & 0 \\
\hline & Total & $8(53.33)$ & $7(46.67)$ & $15(100)$ \\
\hline \multirow[t]{5}{*}{$\beta$-Thalassaemia Trait } & $<1-10$ & $15(19.74)$ & $9(11.84)$ & $24(31.58)$ \\
\hline & $11-20$ & $8(10.53)$ & $8(10.53)$ & $16(21.05)$ \\
\hline & $21-30$ & $3(3.95)$ & $11(14.47)$ & $14(18.42)$ \\
\hline & $>30$ & $12(15.78)$ & 10(13.16) & $22(28.95)$ \\
\hline & Total & $38(50.00)$ & $38(50.00)$ & $76(100)$ \\
\hline \multirow[t]{5}{*}{$\mathrm{Hb} \mathrm{E}$ trait } & $<1-10$ & $15(23.80)$ & $9(14.28)$ & $24(38.09)$ \\
\hline & $11-20$ & $6(9.52)$ & $6(9.52)$ & $12(19.04)$ \\
\hline & $21-30$ & $4(6.34)$ & $13(20.63)$ & $17(26.98)$ \\
\hline & $>30$ & $4(6.34)$ & $6(9.52)$ & $10(6.30)$ \\
\hline & Total & $29(46.00)$ & $34(53.95)$ & $63(90.41)$ \\
\hline
\end{tabular}

Table 1 shows majority number of different types of thalassaemia patients is between (1-10) years and lowest is after 30 years of age.

\section{DISCUSSION}

Thalassaemia is a genetic disorder highly prevalent in our country affecting both sex. This disease is one of the morbid condition causing burdens to our society ${ }^{2}$. In this study of 290 patients, $152(52.4 \%)$ were males and 138 $(47.6 \%)$ were females. This difference was insignificant ( $p$ value $>0.05$ ). This could be due to the gender bias in Bangladesh as male children are given priority while seeking medical care.

The individual percentage of $\mathrm{Hb} \mathrm{E} \beta$-Thalassaemia was $40.34 \%, \beta$-Thalassaemia Major 6.55\%, $\mathrm{Hb}$ E Disease $5.17 \%, \beta$-Thalassaemia trait $26.21 \%$ and $\mathrm{Hb} \mathrm{E}$ trait $21.72 \%$. The percentage of $\mathrm{Hb} \mathrm{E} \beta$-Thalassaemia patients was the highest. This data indicates that $\mathrm{Hb} \mathrm{E} \beta-$ Thalassaemia is most common form in this region. On the other hand, $\mathrm{Hb} \mathrm{E}$ Disease is less common variant of Haemoglobinopathies. Another study performed by Uddin et al in Dhaka city found $\mathrm{Hb}$ E $\beta$ was the second common variety $(13.5 \%)$ of Haemoglobinopathies ${ }^{6}$.

This findings suggested that among all types of thalassaemia the incidence of HBE Beta Thalassaemia patient is very high and in every case the incidence was high in the age group between $<1-10$ years. Though in other age groups the number of thalassaemia patient are also high indicating significant number of thalassaemia in all age groups irrespective of sex. 
In our study, there were $52.07 \%$ were diseased and $47.93 \%$ were trait. This indicate the diseased patients were more than Thalassaemia trait and their differences were found statistically insignificant $(\mathrm{p}>0.05)$. This diseased patient may require frequent or infrequent blood transfusion making a financial burden to their family. They will have iron over load which will require iron chelation. Frequent blood transfusion may also cause transfusion transmitted diseases. On the other hand thalassaemia trait patient are healthy with mild anaemia and can perform normal life style. But before marriage their life partner should be screened to see their carrier status. In this way a thalassaemia disease free child birth can be possible.

\section{CONCLUSION}

A high prevalence of Thalassaemia in Bangladeshis has become a major health burden. HbE- $\beta$ Thalassaemia was found to be the most common type. Carrier detection and mass awareness can help to prevent Thalassaemia and avoid it from being an epidemic in the future. This study gives a demographic data of different spectrum of Haemoglobinopathies and Thalassaemia in Chittagong. This may be helpful to control Thalassaemia and useful for further research on this field.

\section{ACKNOWLEDGEMENT}

The authors gratefully acknowledge the contribution of all staffs and doctors working in the Thalassaemia Ward, Chattagram Maa Shishu-O-General Hospital (CMSOGH). Logistic support for the study was arranged by Director (Admin) CMSOGH. We would like to express gratitude to honorable Head of the department of Pathology and Head of the department of Pediatrics, Chattagram Maa-O-Shishu Hospital Medical College (CMOSHMC) for their valuable advice and guidance.

\section{DISCLOSURE}

All the authors declared no competing interest.

\section{REFERENCES}

1. Modell B, Darlison M. Global epidemiology of haemoglobin disorders andderived service indicators. Bull World Health Organ. 2008;86:480-487.

2. Khan WA, Banu B, Amin SK, Selimuzzaman M, Rahman M, Hossain B et al. Prevalence of beta thalassemia trait and Hb E trait in Bangladeshi school children and health burden of thalassemia in our population. DS HJ. 2005;21(1):1-7.

3. Chowdhury MA, Ullah M, Sultana R. Prevalence of Beta Thalassaemia trait and $\mathrm{Hb}$ E trait in school Children in greater Chittagong: A health burden in our population. CMSOGHJ. 2011;10:7-10.

4. Khan W A. Thalassaemia in Bangladesh. DS (Children) H J. 1999; 15: 42.

5. MannanA,Kawser J, Ahmed AMA, Sikder OF, Islam J, Chowdhury MA. A Demographic Approach for Understanding the Prevalence of Thalassemia Patterns and Other Hemoglobinopathies: Selective Study in Chittagong City Perspective. Asian Journal of Biological Science. 2013; 6: 124-130.

6. Uddin M M, Akteruzzaman S, Rahman T, Hasan A K M M \& Shekhar H U. Pattern of $\beta$-Thalassemia and Other Haemoglobinopathies: A Cross-Sectional Study in Bangladesh. ISRN Hematol. 2012; 10.5402/2012/659191. 